\title{
Efficacy and safety of denosumab compared to bisphosphonates in improving bone strength in postmenopausal osteoporosis: a systematic review
}

Thulasi $\underline{\text { Chandran }}^{1}$, MMed, FCFP, Indumathi $\underline{\text { Venkatachalam }}^{2}$, FRACP, MPH

INTRODUCTION Osteoporosis is the main cause of fractures among women after menopause. This study aimed to evaluate the efficacy and safety of denosumab compared to bisphosphonates in treating postmenopausal osteoporosis. METHODS Databases including PubMed and the Cochrane Central Register of Controlled Trials were systematically searched for randomised controlled trials (RCTs) that directly compared denosumab and bisphosphonates. RCTs that studied both denosumab and bisphosphonates in postmenopausal women with osteoporosis and had a Jadad score $\geq 3$ were included.

RESULTS Nine studies were eligible for inclusion. They were further categorised into six cohort groups. All studies had denosumab with oral bisphosphonates as the active comparator. Four out of six cohort studies showed significant improvements in bone strength $(p<0.001)$ at the distal radius, tibia, total hip, femoral neck, lumbar spine and trochanter at 12 months for patients on denosumab compared to the bisphosphonate group. Serum C-telopeptide of cross-linked collagen, a bone turnover marker, was consistently lower in the denosumab group in all studies. There were no significant differences in hypocalcaemia, atypical fractures, fragility fractures, osteonecrosis of the jaw, all infections (including fever or influenza-like symptoms), gastrointestinal side effects or dermatological conditions in all studies, except for one that did not document side effects.

CONCLUSION Denosumab can be used both as a first-line agent and an alternative to bisphosphonate in the treatment of postmenopausal osteoporosis. There is currently insufficient data to show that denosumab is not inferior to bisphosphonates in fracture prevention.

Keywords: bisphosphonates, bone strength, denosumab, efficacy, postmenopausal osteoporosis

\section{INTRODUCTION}

Osteoporosis is a chronic and progressive condition characterised by decreased bone mass and microarchitectural (geometry) deterioration. The resultant bone fragility increases fracture risk. Women are more prone to osteoporosis, as they can lose up to $20 \%$ of their bone mass in the 5-7 years following menopause. After menopause, including surgical menopause resulting from bilateral oophorectomy, the fall in the production of oestrogen (the hormone that protects bones) leads to bone loss and increases the risk of fractures.

Over the last 30 years in Singapore, cases of hip fractures have increased fivefold in women aged $\geq 50$ years and 1.5 -fold in men of the same age group. The age-adjusted hip fractures rates among women aged $>50$ years are about 450 out of 100,000. (1) $^{(1)}$ In Singapore, the number of hip fractures per year is projected to increase from 1,300 in 1998 to 9,000 in 2050 because of the ageing population. ${ }^{(2)}$ An analysis of patients who sustained osteoporotic hip fractures in Singapore found that they had a mortality of $20 \%$ at two years. Of the survivors, $20 \%$ became semi- or fully dependent, and $42 \%$ became less or non-ambulant. Only $8 \%$ were cared for by chronic healthcare facilities, suggesting that the main social and economic burden was borne by the families of those affected. ${ }^{(2)}$

Fracture risk is measured by bone strength, which is determined by factors such as bone geometry, porosity and mineral properties, ${ }^{(3)}$ and has different methods of measurement. With technological improvements, our understanding of fracture risk at sites dominated by cortical bones has developed beyond bone density. ${ }^{(4,5)}$

Antiresorptive agents such as bisphosphonates, calcitonin, oestrogen and oestrogen agonists/antagonists, and the anabolic drug teriparatide are widely available for the treatment of osteoporosis. Bisphosphonates are commonly used but limited by adverse effects such as oesophagitis, gastritis, jaw osteonecrosis and atypical femoral fractures. Bisphosphonates are also contraindicated in patients with creatinine clearance $\leq 35 \mathrm{~mL} / \mathrm{min}$.

Denosumab, a novel antiresorptive agent, also inhibits osteoclast-mediated bone resorption but works through a different pathway from bisphosphonates. Denosumab ${ }^{(6)}$ binds with high affinity and specificity to RANKL (receptor activator of nuclear factor-kappa B ligand), prevents it from binding with RANK (receptor activator of nuclear factor-kappa B) receptors on osteoclasts and osteoclast precursors, and hence inhibits the synthesis, activity and lifespan of existing osteoclasts. In turn, denosumab inhibits bone resorption and remodelling, as defined by increases in bone mineral density (BMD) and reduction in porosity ${ }^{(3)}$ at all measured skeletal sites, and decreases in biochemical markers of bone turnover. ${ }^{(7)}$ Denosumab can be the better choice between the two drugs, as it is better tolerated

${ }^{1}$ St Andrew's Community Hospital, ${ }^{2}$ Department of Infectious Diseases, Singapore General Hospital, Singapore

Correspondence: Dr Thulasi Chandran, Associate Consultant, St Andrew’s Community Hospital, 8 Simei Street 3, Singapore 529895. thulasi74@hotmail.com 


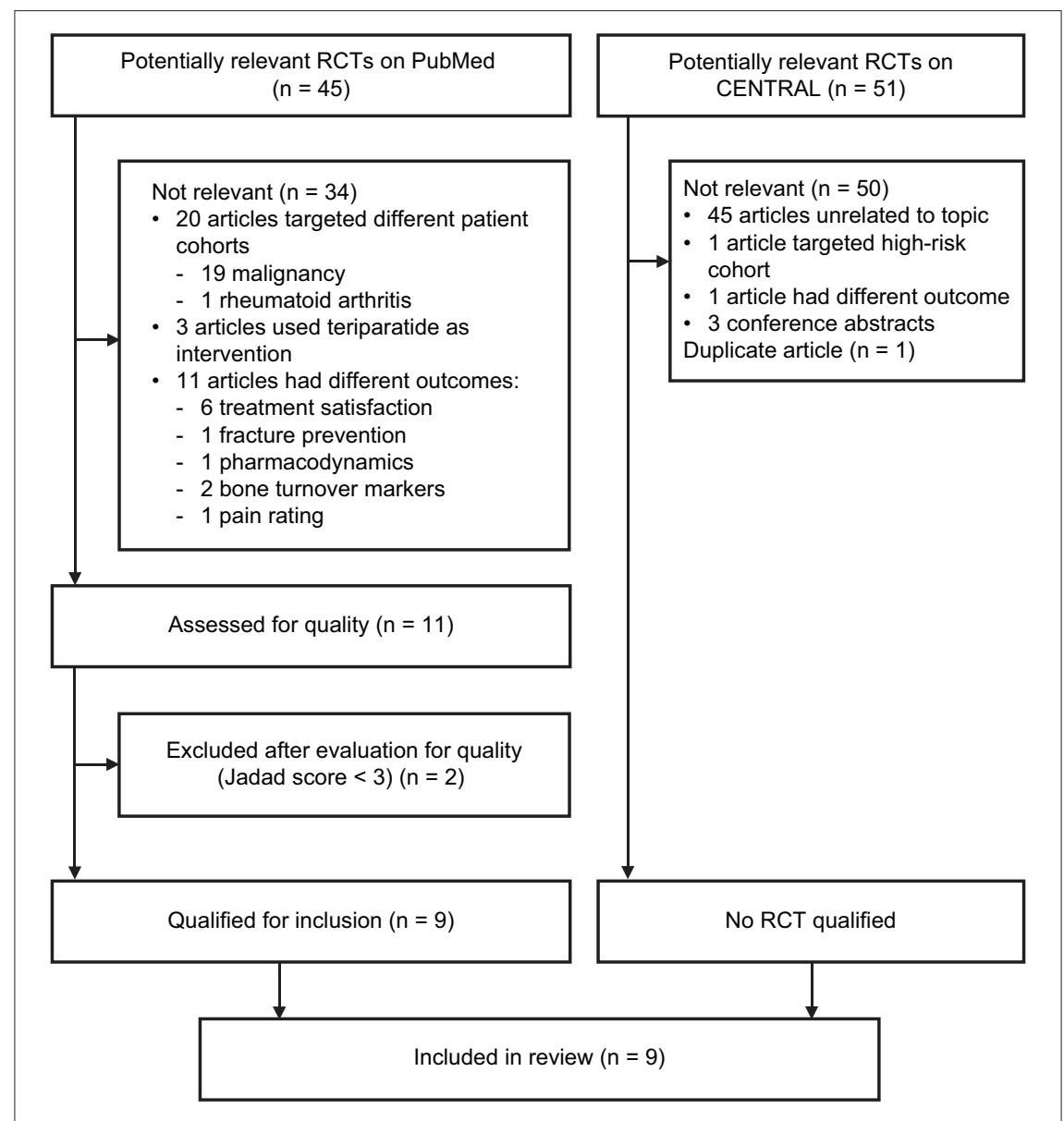

Fig. 1 Flow diagram shows the literature screening process. CENTRAL: Cochrane Central Register of Controlled Trials; RCT: randomised controlled trial

than bisphosphonates and easily administered through two annual injections, which may possibly increase the compliance rate. However, denosumab is slightly more costly than bisphosphonates, and has been hypothesised to increase risk for infection and malignancy. ${ }^{(8)}$

The different mechanisms by which bisphosphonates and denosumab inhibit bone resorption raise the question of how these two agents compare with respect to efficacy measurements and safety profile. Many randomised controlled trials (RCTs) are currently comparing denosumab or bisphosphonates to a placebo, to evaluate their efficacy. Six systematic reviews compared denosumab with bisphosphonates; two meta-analyses used vertebral fracture as the endpoint, ${ }^{(9,10)}$ while two other reviews used differences in BMD changes ${ }^{(11)}$ and fragility fractures ${ }^{(12)}$ as endpoints in indirect head-to-head comparisons. Two other studies compared denosumab with only specific bisphosphonates (ibandronate and risedronate, or alendronate alone). ${ }^{(13,14)}$

We performed this systematic review of RCTs that have conducted head-to-head comparisons of denosumab and bisphosphonates to evaluate their efficacy and safety in treating postmenopausal osteoporosis.

\section{METHODS}

Databases including PubMed and the Cochrane Central Register of Controlled Trials (CENTRAL) were systematically searched for RCTs that directly compared denosumab and bisphosphonates
(Fig. 1). As denosumab is a new drug in the market, a time limit was not set in the search. The following Medical Subject Headings terms were used: 'denosumab' and 'bisphosphonates', and the search was limited to RCT trials that matched the filter. A free text search was also carried out. Citations and reference lists of relevant articles were checked for additional studies. RCTs that studied both denosumab and bisphosphonates in postmenopausal women with osteoporosis and had a Jadad score $\geq 3$ were included.

The following data was extracted from each included study: (a) study design; (b) study quality based on Jadad score (those with a score $<3$ were excluded); (c) study population (i.e. age group, prior bisphosphonate treatment and duration, location and 25-hydroxy vitamin D level); (d) intervention (i.e. dose of denosumab); (e) comparator (i.e. types and doses of bisphosphonates and placebo); (f) follow-up duration; (g) dropout numbers; (h) primary outcome (i.e. changes in bone mineral density at the hip, lumbar spine, distal radius or distal tibia, and bone porosity and secondary outcome in terms of bone turnover markers and adverse effects); (i) results; and (j) adverse effects. These are summarised in Tables I and II.

\section{RESULTS}

A PubMed search yielded 45 potential articles, of which only nine were relevant and of sufficient quality. A similar search on CENTRAL did not yield any articles that were relevant except for one duplicate study. Two studies with a Jadad score $<3$ 
Table I. Adverse events in the selected studies.

\begin{tabular}{|c|c|c|}
\hline Author, yr & Adverse events of interest in denosumab vs. bisphosphonate treatment group & p-value \\
\hline Anastasilakis et al, 2015(25) & Not reported & - \\
\hline Zebaze et al, 2014(24) & Not reported & - \\
\hline Seeman et al, $2010^{(23)}$ & $\begin{array}{l}\text { Influenza, gastrointestinal side effects and infections were reported to be not significantly } \\
\text { different between the groups }\end{array}$ & No p-value \\
\hline \multirow[t]{2}{*}{ Recknor et al, 2013 } & Hypocalcaemia, fractures, hypersensitivity, eczema, infections, malignancies, cardiac disorders & $>0.05$ \\
\hline & Gastrointestinal disorders, respiratory disorders more frequent in denosumab group & $<0.05$ \\
\hline Kendler et al, 2010(21) & Clinical fractures, gastrointestinal disorders, infections, neoplasms & $>0.05$ \\
\hline Brown et al, 2009(20) & $\begin{array}{l}\text { Gastrointestinal disorders, infections, neoplasms (benign or malignant), all fractures, } \\
\text { osteoporotic fractures }\end{array}$ & $>0.05$ \\
\hline Miller et al, $2008^{(19)}$ & Infections, fractures (including osteoporotic fractures) & $>0.05$ \\
\hline \multirow[t]{2}{*}{ Lewiecki et al, $2007^{(18)}$} & Upper respiratory tract infection, influenza, gastro-oesophageal reflux disease, diarrhoea & $>0.05$ \\
\hline & Dyspepsia and osteoarthritis greater in denosumab group & $<0.05$ \\
\hline McClung et al, $2006^{(17)}$ & Infections, cardiac disorders, clinical fractures, rash, hypocalcaemia & $>0.05$ \\
\hline
\end{tabular}

were excluded: the first study by Roux et $\mathrm{al}^{(15)}$ was a post-hoc analysis with a sample population that was highly selective and not representative of the study population. In the other study by Beck et al, ${ }^{(16)}$ the randomisation method was not explained, and withdrawals and dropouts were not fully accounted for. The Jadad score was used to assess the methodological quality of the nine selected papers, ${ }^{(17-25)}$ which were all RCTs. Five studies had a Jadad score of $3,^{(17-19,22,25)}$ one study had a score of $4^{(24)}$ and three studies had a score of $5 .^{(20,21,23)}$ The nine studies were based on six different study cohorts: three articles ${ }^{(17-19)}$ assessed outcomes in a single original cohort at different time points and two articles reported different modalities for bone strength measurement for the same study cohort. ${ }^{(23,24)}$

Among the nine selected RCTs, the study populations ranged from age 60.5 to 68.1 years. Time since menopause, reported for four study cohorts, ${ }^{(17,19-22)}$ varied from 13.1 to 20.4 years. BMD scores, based on dual-energy X-ray absorptiometry (DEXA) results of the hip or lumbar spine, ranged from -2.0 to -4.0 . Most of the study cohorts were multicentre and international, with populations from Argentina, Australia, Canada, France, Western Europe, and North and South America, except for those by Lewiecki et al, Miller et al and McClung et al, which involved the same group of participants from 29 study centres confined to the United States. The biggest trial, conducted by Brown et al, ${ }^{(20)}$ comprised 1,189 participants from 86 sites in Western Europe, North and South America, and Australia. The smallest trial was conducted by Anastasilakis et al, ${ }^{(25)}$ with only 64 participants.

Three studies included original patient cohorts who had previously used bisphosphonates. ${ }^{(21,22,25)}$ Intravenous zoledronic acid treatment was given for one year in the study by Anastasilakis et $\mathrm{al}^{(25)}$ in 2015 before the participants either received more intravenous zoledronic acid or denosumab. Recknor et al's study in 2013 included patients who received at least one month of bisphosphonate before screening but had either discontinued bisphosphonate treatment or had insufficient adherence score $<6$ on the Osteoporosis-Specific Morisky Medication Adherence Scale. ${ }^{(22)}$ In Kendler et al's 2010 study, (21) participants were required to have received $70 \mathrm{mg}$ of alendronate-equivalent for at least six months, and all subjects received open-label, branded alendronate $70 \mathrm{mg}$ once weekly for a one-month run-in period prior to randomisation. The other studies recruited patients who had no prior bisphosphonates use.

As their inclusion criteria, three cohort studies ${ }^{(21,22,24,25)}$ required vitamin $\mathrm{D}$ level to be screened. Out of the three study cohorts, two ${ }^{(21,24,25)}$ recruited participants with vitamin D level $\geq 12 \mathrm{ng} / \mathrm{mL}$, while the other ${ }^{(22)}$ recruited participants with vitamin D level $>20 \mathrm{ng} / \mathrm{mL}$. The rest of the three study cohorts ${ }^{(17-19,22,25)}$ did not use vitamin D level as selection criteria.

Eight studies had denosumab with oral bisphosphonates as the active comparator, while one study had intravenous bisphosphonate instead. Three study cohorts ${ }^{(17-19,23,24)}$ included placebo controls. Doses of denosumab were kept at $60 \mathrm{mg}$ subcutaneously every six months except for the extension trials, ${ }^{(17-19)}$ which had varying doses of subcutaneous denosumab $6 \mathrm{mg}, 14 \mathrm{mg}$ or $30 \mathrm{mg}$ every three months and $14 \mathrm{mg}$, $60 \mathrm{mg}, 100 \mathrm{mg}$ or $210 \mathrm{mg}$ every six months. Alendronate $70 \mathrm{mg}$ once weekly was the choice of oral bisphosphonate in all trials except for two studies, one by Recknor et al, ${ }^{(22)}$ which used ibandronate $150 \mathrm{mg}$ once per month, and the other by Anastasilakis et al, ${ }^{(25)}$ which used an intravenous infusion of zoledronic acid $5 \mathrm{mg}$.

The nine studies had various primary outcomes, including percentage change in BMD at the hip ${ }^{(19-22)}$ and lumbar spine ${ }^{(17-19)}$ from baseline using DEXA; and change in total cortical and trabecular BMD at the distal radius and distal tibia ${ }^{(23)}$ from baseline using high-resolution peripheral quantitative computed tomography (HR-pQCT). One study reported change in bone porosity ${ }^{(24)}$ of the cortex and trabecular bone at the distal radius and tibia based on HR-pQCT findings. Measurements at the femoral neck, lumbar spine and lumbar radius were included as secondary outcome measures in different studies. All studies included serum bone turnover markers, serum C-telopeptide of cross-linked collagen (CTX) or procollagen type $1 \mathrm{~N}$-terminal propeptide (P1NP), or both. Two studies ${ }^{(17,25)}$ included calcium and parathyroid hormone levels as the secondary outcomes. The selected studies are outlined in Table II. 
Except for two extension studies by Lewiecki et al and Miller et al, ${ }^{(18,19)}$ which conducted 24 and 48 months of followup, respectively, the rest of the study cohorts followed up the patients for 12 months. Eight ${ }^{(17-23,25)}$ out of nine papers measured BMD, while one study ${ }^{(24)}$ measured porosity. Of the eight, six used alendronate as the comparator, one used ibandronate ${ }^{(22)}$ and the other used intravenous zoledronic acid. ${ }^{(25)}$ Bone strength was measured at the following sites - total hip, femoral neck, trochanter, lumbar spine, distal radius and distal tibia.

Three papers ${ }^{(17-19)}$ that assessed outcomes at 12, 24 and 48 months for the same cohort had multiple arms with different doses of subcutaneous denosumab. In McClung et al's $\mathrm{s}^{(17)}$ report in 2006, results at 12 months showed that the change in BMD from baseline at the lumbar spine was a $3.0 \%-6.7 \%$ increase for denosumab compared to a $4.6 \%$ increase for alendronate and a $0.8 \%$ decrease for the placebo. The corresponding changes at the total hip were a $1.9 \%-3.6 \%$ increase for denosumab, $2.1 \%$ increase for alendronate and $-0.6 \%$ decrease for the placebo. At the distal one-third radius, there was a $0.4 \%-1.3 \%$ increase for denosumab, and a $0.5 \%$ decrease and $2.0 \%$ decrease in the alendronate and placebo groups, respectively. These authors did not report if the percentage change in BMD for denosumab was significantly different from that for alendronate.

As reported in $2007,{ }^{(18)}$ at 24 months, the denosumab group experienced similar bone density changes at all four skeletal sites compared to the alendronate group. Significant improvements in bone density $(p<0.001)$ from baseline were also reported with alendronate and denosumab at the lumbar spine when compared with a placebo. Although there was a significant increase in BMD with denosumab and alendronate use when compared to a placebo, the difference between the effects of denosumab and alendronate on BMD were not compared in this study. The same cohort was followed up over 48 months in a 2008 extension study, ${ }^{(19)}$ in which alendronate was discontinued at 24 months. When denosumab was continued for 48 months, BMD increased from $9.4 \%$ to $11.8 \%$ at the lumbar spine compared to a $-2.4 \%$ decrease for the placebo group $(p<0.001)$ and $4.0 \%$ to $6.1 \%$ at the hip compared to a $-3.5 \%$ decrease for the placebo group $(p<0.001)$. Patients for whom alendronate was discontinued at 24 months had a decrease in BMD at the lumbar spine, total hip and distal radius. A similar RCT by Brown et al in 2009, ${ }^{(20)}$ conducted on 1,189 patients, showed a statistically significant treatment difference in BMD at 12 months when denosumab was compared with alendronate, with a $0.9 \%$ increase at the total hip, $1.1 \%$ increase at the trochanter, $0.5 \%$ increase at the one-third radius, $0.6 \%$ increase at the femoral neck and $1.1 \%$ increase at the lumbar spine ( $\mathrm{p} \leq 0.0002$ all sides). Kendler et $\mathrm{a}^{(21)}$ demonstrated in 2010 that denosumab increased BMD significantly by $0.85 \%$ $(p<0.0001)$ and $1.18 \%(p<0.0001)$ at the total hip and lumbar spine, respectively, compared to alendronate. Increase in BMD was also observed at the femoral neck and one-third radius at 12 months; however, it was not significant $(p<0.0121)$.

In the only study that used ibandronate as the comparator, ${ }^{(22)}$ denosumab was significantly better than ibandronate at improving bone density. At 12 months, BMD gain at the total hip was $2.3 \%$
(95\% confidence interval $[\mathrm{Cl}] 2.0 \%-2.5 \%$ ) in the denosumab group and $1.1 \%(95 \% \mathrm{Cl} 0.9 \%-1.4 \%)$ in the ibandronate group $(p<0.001)$. Corresponding BMD changes were $1.7 \%$ and $0.7 \%$ $(p<0.001)$ at the femoral neck, and $4.1 \%$ and $2.0 \%(p<0.001)$ at the lumbar spine. Hence, a difference of $1.2 \%(p<0.001)$ was noted at the total hip, $1.0 \%(\mathrm{p}<0.001)$ at the femoral neck and $2.1 \%(p<0.001)$ at the lumbar spine.

Anastasilakis et $\mathrm{al}^{(25)}$ conducted the only study that used intravenous bisphosphonate in the form of zoledronic acid. They found that there was no significant difference in BMD gain at the lumbosacral spine between the two treatment types, with a mean increase of $4.5 \%$ for the denosumab group and $4.4 \%$ for the zoledronic acid group ( $p=0.560$ ).

Porosity, as opposed to density, was measured in the study by Zebaze et al in 2014. ${ }^{(24)}$ Denosumab was found to reduce porosity at six months and further reduce it at 12 months, a statistically significant 1.5-to-2.0-fold reduction compared to alendronate at all three cortical regions at the distal radius: compact-appearing cortex $(p=0.012)$, outer cortical transition zone $(p=0.003)$ and inner cortical transitional zone $(p=0.021)$. However, there was no significant difference between denosumab and alendronate in terms of trabecular bone volume/total volume.

In the 2010 study by Seeman et al, ${ }^{(23)}$ the percentage increase in volumetric BMD values between the denosumab and alendronate groups, as found using HR-pQCT, was significantly different for total and cortical vBMD at the distal radius $(p=0.024)$ and distal tibia $(p=0.003)$, but not for trabecular $\mathrm{vBMD}$ and cortical thickness.

Serum CTX was analysed as one of the turnover markers in all studies. The greatest decrease in CTX level was seen with denosumab, as compared to bisphosphonates and a placebo, in all studies. Three studies ${ }^{(20,23,25)}$ also analysed P1NP and showed a reduction in the denosumab group compared to the bisphosphonate group. In the trial conducted by Seeman et al, ${ }^{(23)}$ P1NP suppression was slower than that of CTX in the denosumab group compared to the bisphosphonate group; the nadir occurred by three months and the suppression lessened by the end of the six-month dosing interval. Similar results were also seen with bone-specific alkaline phosphatase. However, calcium and intact parathyroid hormone levels did not show any significant changes.

All studies analysed the adverse effects of denosumab or compared it with a placebo or the bisphosphonate of choice, except for those by Zebaze et $\mathrm{al}^{(24)}$ and Anastasilakis et $\mathrm{al}^{(25)}$ (Table I). Among the antiresorptive agents, the adverse effects that were of interest were hypocalcaemia, atypical fractures, fragility fractures, osteonecrosis of the jaw, all infections (including fever or influenza-like symptoms), gastrointestinal side effects and dermatological conditions. In one study, ${ }^{(22)}$ the incidence of serious adverse events, including gastrointestinal and respiratory disorders, were significantly higher $(p<0.05)$ in the denosumab group than the ibandronate group. In another, there was a significantly higher incidence of dyspepsia and osteoarthritis in the alendronate group compared to the denosumab group. ${ }^{(18)}$ There were no significant differences in adverse events for the rest of the studies. 


\section{Table II. Summary of the randomised control trials.}

\begin{tabular}{|c|c|c|c|c|}
\hline \multicolumn{5}{|l|}{ McClung et al (2006) $)^{(17)}$} \\
\hline \multirow{2}{*}{$\begin{array}{l}\text { Study design } \\
\text { Jadad score } 3 \text {, double-blind placebo-controlled RCT, including } 8 \text { double-blind treatment groups and } \\
1 \text { open-label treatment group }\end{array}$} & \multicolumn{4}{|l|}{ Results } \\
\hline & $\begin{array}{l}\text { Mean change of BMD from } \\
\text { baseline at } 12 \mathrm{mth}^{*}(\%)\end{array}$ & Placebo & Denosumab & Alendronate \\
\hline Study population & Lumbar spine & -0.8 & $3.0-6.7$ & 4.6 \\
\hline \multirow{2}{*}{$\begin{array}{l}\text { Postmenopausal women; age } \leq 80 \mathrm{yr} \\
\text { BMD: lumbar spine }-1.8 \text { to }-4.0 \text { or total hip or femoral neck }-1.8 \text { to }-3.5\end{array}$} & Total hip & -0.6 & $1.9-3.6$ & 2.1 \\
\hline & Distal $1 / 3$ radius & -2.0 & $0.4-1.3$ & -0.5 \\
\hline 29 study centres in US; $n=412$; follow-up duration: 12 mth; dropout rate: $10 \%$ & \multirow{9}{*}{\multicolumn{4}{|c|}{$\begin{array}{l}\text { *p-values for denosumab and placebo at lumbar spine, total hip and distal } 1 / 3 \text { radius are }<0.001 \text {. } \\
\text { Near maximal reductions in mean levels of CTX from baseline were evident } 3 \text { days after the } \\
\text { administration of denosumab. The duration of the suppression of bone turnover appeared } \\
\text { to be dose-dependent. }\end{array}$}} \\
\hline $\begin{array}{l}\text { Exclusion: } \\
\text { 1. Use of bisphoshonates within } 12 \mathrm{mth} \text { or fluoride within } 24 \mathrm{mth} \\
\text { 2. Tibolone, PTH, systemic glucocorticoids }>5 \mathrm{mg} \text { for }>10 \text { days, inhaled glucocorticoids, anabolic } \\
\text { steroids/testosterone within } 6 \mathrm{mth} \text {, oestrogens, selective oestrogen receptor modulator, calcitonin or } \\
\text { calcitriol } \\
\text { 3. Women with hyper or hypothyroidism, hyper- or hypoparathyroidism, hypocalcaemia, rheumatoid } \\
\text { arthritis, Paget's disease of the bone, osteomalacia, } \mathrm{CrCl} \leq 35 \mathrm{~mL} / \mathrm{min} \text {, malabsorption syndrome, } \\
\text { recent long-bone fracture within } 6 \mathrm{mth} \text {, or }>1 \mathrm{Grade} 1 \mathrm{vertebral} \text { fracture or an osteoporosis-related } \\
\text { fracture within the last } 2 \mathrm{yr}\end{array}$ & & & & \\
\hline Intervention & & & & \\
\hline $\begin{array}{l}\text { Double blind: placebo or denosumab } \\
\text { - SC denosumab every } 3 \mathrm{mth}: 6 \mathrm{mg}(\mathrm{n}=4) ; 14 \mathrm{mg}(\mathrm{n}=44) ; 30 \mathrm{mg}(\mathrm{n}=41) \\
\text { - } \mathrm{SC} \text { denosumab every } 6 \mathrm{mth}: 14 \mathrm{mg}(\mathrm{n}=5) ; 60 \mathrm{mg}(\mathrm{n}=47) ; 100 \mathrm{mg}(\mathrm{n}=42) ; 210 \mathrm{mg}(\mathrm{n}=47) \\
\text { - } \quad \text { SC placebo every } 3 \mathrm{mth}(\mathrm{n}=46)\end{array}$ & & & & \\
\hline Comparator & & & & \\
\hline Open-label trial: oral alendronate 70 mg once per wk $(n=47)$ & & & & \\
\hline Outcome measure & & & & \\
\hline$\frac{\text { Primary }}{\text { Percentage change in BMD at the lumbar spine at baseline, } 3,6 \text { and } 12 \mathrm{mth} \text { using DEXA }}$ & & & & \\
\hline $\begin{array}{l}\text { Secondary } \\
\text { 1. Percentage change from baseline in BMD at the total hip, femoral neck, total body (minus head), and } \\
\text { distal third of the radius at } 3,6 \text { and } 12 \mathrm{mth} \text { using DEXA } \\
\text { 2. CTX, ALP, albumin-adjusted serum calcium, iPTH at baseline, } 1,3,6 \text { and } 12 \mathrm{mth} \\
\text { 3. Adverse drug events }\end{array}$ & & & & \\
\hline
\end{tabular}




\section{Table II. (Contd...)}

\begin{tabular}{|c|c|c|c|c|}
\hline \multicolumn{5}{|l|}{ Lewiecki et al (2007)(18) } \\
\hline Study design & \multicolumn{4}{|l|}{ Results } \\
\hline $\begin{array}{l}\text { Extension study, Jadad score } 3 \text {, double-blind placebo-controlled RCT, including } 8 \text { double-blind treatment } \\
\text { groups and } 1 \text { open-label treatment group }\end{array}$ & $\begin{array}{l}\text { Mean change of BMD from } \\
\text { baseline at } 24 \mathrm{mth}(\%)\end{array}$ & Denosumab & Placebo & p-value \\
\hline Study population & \multirow{2}{*}{ Lumbar spine } & \multirow{2}{*}{$\begin{array}{l}\text { 4.13-8.89 increase for all doses of } \\
\text { denosumab }\end{array}$} & \multirow[t]{2}{*}{-1.88} & \multirow[t]{2}{*}{$<0.001$} \\
\hline \multirow{2}{*}{$\begin{array}{l}\text { Postmenopausal women; age } \leq 80 \mathrm{yr} \\
\text { BMD: lumbar spine }-1.8 \text { to } 4.0 \text { or total hip }-1.8 \text { to }-3.5 \\
29 \text { study centres in US; } n=412 ; \text { follow-up duration: } 24 \text { mth; dropout rate: } 18 \%\end{array}$} & & & & \\
\hline & Total hip & $\begin{array}{l}\text { Significant increase compared to } \\
\text { placebo }\end{array}$ & - & $<0.001$ \\
\hline $\begin{array}{l}29 \text { study centres in US; } \mathrm{n}=412 \text {; follow-up duration: } 24 \text { mth; dropout rate: } 18 \% \\
\text { Intervention }\end{array}$ & Distal $1 / 3$ radius & $\begin{array}{l}\text { Significant increase compared to } \\
\text { placebo }\end{array}$ & - & $<0.001$ \\
\hline $\begin{array}{l}\text { Double blind: placebo or denosumab } \\
\text { - SC denosumab every } 3 \mathrm{mth}: 6 \mathrm{mg}(\mathrm{n}=44) ; 14 \mathrm{mg}(\mathrm{n}=44) ; 30 \mathrm{mg}(\mathrm{n}=41) \\
\text { - SC denosumab every } 6 \mathrm{mth}: 14 \mathrm{mg}(\mathrm{n}=54) ; 60 \mathrm{mg}(\mathrm{n}=47) ; 100 \mathrm{mg}(\mathrm{n}=42) ; 210 \mathrm{mg}(\mathrm{n}=46) \\
\text { - } \mathrm{SC} \text { placebo every } 3 \mathrm{mth}(\mathrm{n}=46)\end{array}$ & \multirow{3}{*}{\multicolumn{4}{|c|}{$\begin{array}{l}\text { Denosumab vs. alendronate at } 24 \mathrm{mth} \\
\text { BMD changes with denosumab } 30 \mathrm{mg} \text { every } 3 \mathrm{mth} \text { and } \geq 60 \mathrm{mg} \text { every } 6 \mathrm{mth} \text {, similar to } \\
\text { or in some instances greater than alendronate at all four skeletal sites, with the exception } \\
\text { of the } 14-\mathrm{mg} 6 \text {-mth dose, in which the change in lumbar spine BMD was less than with } \\
\text { alendronate treatment }(p=0.02)\end{array}$}} \\
\hline \multirow{2}{*}{$\begin{array}{l}\text { Comparator } \\
\text { Open-label trial: oral alendronate } 70 \mathrm{mg} \text { once per wk }(n=47)\end{array}$} & & & & \\
\hline & & & & \\
\hline Outcome measure & \multicolumn{4}{|c|}{ Alendronate vs. placebo at $24 \mathrm{mth}$} \\
\hline \multirow[t]{2}{*}{$\begin{array}{l}\text { Primary } \\
\text { Percentage from baseline in BMD at the lumbar spine, total hip, distal } 1 / 3 \text { radius and total body } \\
\text { (minus head) at } 24 \mathrm{mth} \text { using DEXA }\end{array}$} & \multicolumn{4}{|c|}{$\begin{array}{l}\text { Alendronate increased BMD significantly }(p<0.001) \text { compared to placebo at lumbar spine, } \\
\text { distal } 1 / 3 \text { radius, total body and total hip }\end{array}$} \\
\hline & \multicolumn{4}{|l|}{ CTX level } \\
\hline \multirow{8}{*}{$\begin{array}{l}\text { Secondary } \\
\text { Percentage change from baseline in bone turnover markers at } 24 \mathrm{mth} \text { and safety }\end{array}$} & \multicolumn{4}{|c|}{ Denosumab vs. placebo at $24 \mathrm{mth}$} \\
\hline & \multicolumn{4}{|c|}{ Decreased concentration compared to placebo at $24 \mathrm{mth}$} \\
\hline & \multicolumn{4}{|l|}{ Denosumab vs. alendronate } \\
\hline & \multicolumn{4}{|c|}{ Reductions in alendronate were less than those observed with higher doses of denosumab } \\
\hline & \multicolumn{4}{|l|}{ ALP level } \\
\hline & \multicolumn{4}{|c|}{$\begin{array}{l}\text { Reductions in bone-specific alkaline phosphatase levels were significantly greater with } \\
\text { denosumab treatment compared with placebo }\end{array}$} \\
\hline & \multicolumn{4}{|l|}{ Calcium and iPTH levels } \\
\hline & \multicolumn{4}{|c|}{ No significant changes noted in calcium or iPTH levels } \\
\hline
\end{tabular}


Table II. (Contd....)

\section{Miller et al (2008)(19)}

\section{Study design}

Extension study, Jadad score 3, double-blind placebo-controlled RCT, including 8 double-blind treatment groups and 1 open-label treatment group

\section{Study population}

Extension study of Lewiecki et al, ${ }^{(18)}$ assessing the long-term efficacy and safety of denosumab and the effects of discontinuing and restarting denosumab treatment in postmenopausal women with low bone mass.

Postmenopausal women; age $\leq 80 \mathrm{yr}$

BMD: lumbar spine -1.8 to 4.0 or total hip -1.8 to -3.5

Received $2 \mathrm{yr}$ of denosumab

29 study centres in US; $\mathrm{n}=412$; follow-up duration: $24-48 \mathrm{mth}$; dropout rate: $36 \%$

\section{Intervention}

Double-blind: placebo or denosumab

- Groups from the original cohort, receiving denosumab $6 \mathrm{mg} \mathrm{Q3M,} 14 \mathrm{mg}$ Q3M, $14 \mathrm{mg} \mathrm{Q6M,} 60 \mathrm{mg}$

Q6M, $100 \mathrm{mg}$ Q6M till $24 \mathrm{mth}$ continued on $60 \mathrm{mg}$ Q6M dosing from 24 to $48 \mathrm{mth}$ $(n=231)$

- Group receiving SC denosumab $210 \mathrm{mg}$ Q6M stopped treatment after $24 \mathrm{mth}(\mathrm{n}=46)$

- Group receiving SC denosumab $30 \mathrm{mg}$ Q3M stopped treatment after $24 \mathrm{mth}$ for $1 \mathrm{yr}$, then received SC $60 \mathrm{mg}$ Q6M from 36 to $48 \mathrm{mth}(\mathrm{n}=41)$

- Placebo cohort maintained $(n=46)$

\section{Comparator}

Open-label trial: oral alendronate $70 \mathrm{mg}$ once per week for $24 \mathrm{mth}$, then discontinued from 24 to 48 mth $(n=47)$

\section{Outcome measure}

\section{Primary}

Percentage change in BMD at lumbar spine, hip and distal 1/3 radius using DEXA

Secondary

Bone turnover markers - CTX and bone ALP

\section{Results}

Treatment

Mean change of BMD (\%)

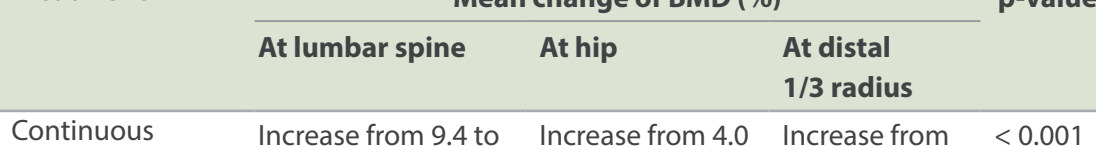

$\begin{array}{llll}\text { denosumab } & \text { Increase from } 9.4 \text { to } & \text { Increase from } 4.0 & \text { Increase } \\ \text { tr.8 for treatment } & \text { to } 6.1, \text { compared } & 1.0 \text { to } 1.7\end{array}$

treatment for group compared with $-3.5 \%$ for compared

$48 \mathrm{mth}$ with -2.4 for placebo the placebo with -4.7 for

$\begin{array}{lll} & \text { group } & \text { placebo }\end{array}$

of SC denosumab within first $12 \mathrm{mth} \quad 5.3$ within 0.8 within

after $24 \mathrm{mth}$ of treatment first $12 \mathrm{mth}$ first $12 \mathrm{mth}$

discontinuation of treatment of treatment

Retreatment discontinuation discontinuation

with denosumab

Increase of 3.9

Increase of 1.8

at 36-48 mth

after stopping

treatment at

24 mth

Discontinuation of Moderate decrease More substantial decreases in BMD -

alendronate after in BMD by Month 48 compared at lumbar spine 24 mth

\section{Treatment}

Bone turnover markers

Continuous long-term denosumab

Consistently suppressed over $48 \mathrm{mth}$

Discontinuing denosumab and

Increased with discontinuation and

retreatment with denosumab

Safety outcomes 


\section{Table II. (Contd...)}

\section{Brown et al (2009) (20)}

\section{Study design}

Jadad score 5, double-blind double-dummy RCT

\section{Study population}

Ambulatory postmenopausal women; mean age $64.1-64.6 \mathrm{yr}$

BMD: T-score $\leq 2.0$ at total hip or lumbar spine by DEXA

86 sites in Western Europe, North and South America, and Australia; $\mathrm{n}=1,189$; follow-up duration:

$21 \mathrm{mth}$; dropout rate: $7.1 \%$

Exclusion:

1. Prior administration of IV BP or fluoride (except for dental treatment) or strontium; use of drugs with known bone activity within $3 \mathrm{mth}$ of randomisation

2. Current enrolment in or $<1 \mathrm{mth}$ since completion of other drug trials

3. Evidence of an active disease known to affect bone metabolism

4. Malignancy within past $5 \mathrm{yr}$ (except basal or squamous cell carcinoma or cervical or breast cancer in situ)

5. Impaired renal function

6. Contraindications for alendronate therapy

7. Vitamin $D$ level $<12 \mathrm{ng} / \mathrm{mL}$ ineligible but could undergo vitamin $D$ repletion with ergocalciferol for 2 wk and be rescreened

\section{Intervention}

SC denosumab: $60 \mathrm{mg} 6$ mthly $(n=594)$

Comparator

Oral alendronate $70 \mathrm{mg}$ weekly $(\mathrm{n}=595)$

\section{Outcome measure}

Primary

Percentage change in total hip BMD at 12 mth by DEXA

Results

\begin{tabular}{|c|c|c|c|c|}
\hline \multirow{2}{*}{$\begin{array}{l}\text { BMD change } \\
\text { at } 12 \mathrm{mth}\end{array}$} & \multicolumn{3}{|c|}{ (\%) } & \multirow[t]{2}{*}{ p-value } \\
\hline & Denosumab & Alendronate & Treatment difference & \\
\hline Total hip & 3.5 & 2.6 & 0.9 & $\leq 0.0002$ \\
\hline Trochanter & 4.5 & 3.4 & 1.1 & $\leq 0.0002$ \\
\hline $1 / 3$ radius & 1.1 & 0.6 & 0.5 & $\leq 0.0002$ \\
\hline Femoral neck & 2.4 & 1.8 & 0.6 & $\leq 0.0002$ \\
\hline Lumbar spine & 5.3 & 4.2 & 1.1 & $\leq 0.0002$ \\
\hline
\end{tabular}

\begin{tabular}{|llll|}
\hline & & (\%) & p-value \\
& Denosumab & Alendronate & \\
\hline CTX (mth) & & & $<0.0001$ \\
\hline 1 & -89 & -61 & $<0.0001$ \\
\hline 3 & -89 & -66 & 0.0001 \\
\hline 6 & -77 & -73 & $<0.0001$ \\
\hline 9 & -89 & -76 & 0.52 \\
\hline 12 & -74 & -76 & $<0.0001$ \\
\hline P1NP (mth) & & & $<0.0001$ \\
\hline 1 & -26 & -11 & $<0.0001$ \\
\hline 3 & -76 & -56 & $<0.0001$ \\
\hline 9 & -78 & -65 & \\
\hline 12 & -72 & -65 & \\
\hline
\end{tabular}

Denosumab showed greater reduction in bone turnover markers compared with alendronate.

\section{Secondary}

1. Percentage change in BMD at femoral neck, trochanter, lumbar spine and $1 / 3$ radius at 12 mth using DEXA

2. Bone turnover markers at 1, 3, 6, 9 and $12 \mathrm{mth}$ : CTX, P1NP

3. Safety-adverse events and lab values

4. Anti-denosumab antibodies 


\section{Table II. (Contd...)}

Kendler et al (2010) $)^{(21)}$

\section{Study design}

Jadad score 5, double-blind double-dummy RCT

\section{Study population}

Ambulatory postmenopausal women; age $>55 \mathrm{yr}$

BMD: lumbar spine or total hip, T-score $\leq-2.0$ to $\geq-4.0$

Receiving treatment equivalent to $70 \mathrm{mg} / \mathrm{wk}$ of alendronate for $\geq 6 \mathrm{mth} ; 1 \mathrm{mth}$ run-in period during

which all subjects received open-label, branded alendronate $70 \mathrm{mg}$ once weekly prior to randomisation

International multicentre trial; $\mathrm{n}=504$; follow-up duration: $12 \mathrm{mth}$; dropout rate: $4.6 \%$

Exclusion:

1. Hyper- or hypothyroidism

2. Hyper- or hypoparathyroidism

3. Elevated transaminases

4. $\mathrm{CrCl} \leq 35 \mathrm{~mL} / \mathrm{min}$ as estimated by Cockcroft and Gault method

5. Hyper- or hypocalcaemia

6. Vitamin D level $<20 \mathrm{ng} / \mathrm{mL}$

7. Any metabolic disease

8. Any BP taken within $1 \mathrm{yr}$ of screening

9. If IV BP was ever taken, fluoride (except for dental treatment)/strontium/PTH/PTH derivatives within $1 \mathrm{yr}$

10. Received any selective oestrogen receptor modulator, anabolic steroids, systemic hormone replacement, calcitonin, calcitriol or other vitamin D within $3 \mathrm{mth}$

11. Had height, weight or girth measurements that precluded accurate DEXA assessments

\section{Intervention}

SC denosumab 60 mg every $6 \mathrm{mth}(\mathrm{n}=253)$

\section{Comparator}

Oral alendronate $70 \mathrm{mg}$ weekly $(\mathrm{n}=253)$

\section{Outcome measure}

Primary

Total hip BMD at 6 and 12 mth using DEXA

Secondary

1. Lumbar BMD at 6 and $12 \mathrm{mth}$

2. Femoral neck BMD at 6 and $12 \mathrm{mth}$

3. $1 / 3$ radius $B M D$ at 12 mth using DEXA

4. CTX and P1NP at $3,6,7,9$ and $12 \mathrm{mth}$

5. Adverse events

Results

\begin{tabular}{|lllll|}
\hline $\begin{array}{l}\text { BMD change } \\
\text { at } \mathbf{1 2} \text { mth }\end{array}$ & \multicolumn{3}{c}{$\%(\mathbf{9 5 \%} \mathbf{C l})$} & p-value \\
\cline { 2 - 4 } & Denosumab & Alendronate & Difference & \\
\hline Total hip & $1.90(1.61-2.18)$ & $1.05(0.76-1.34)$ & $0.85(0.44-1.25)$ & $<0.0001$ \\
\hline Lumbar spine & $3.03(2.63-3.44)$ & $1.85(1.44-2.26)$ & $1.18(0.63-1.73)$ & $<0.0001$ \\
\hline Femoral neck & & & Increase & $\leq 0.0121$ \\
\hline $1 / 3$ radius & & & Increase & $\leq 0.0121$ \\
\hline
\end{tabular}

Significant BMD increases for denosumab compared with alendronate were observed as early as Month 6 at the lumbar spine and femoral sites $(p<0.05)$.

Median serum CTX levels remained near baseline in the alendronate group and were significantly decreased versus alendronate $(p<0.0001)$ at all time points with denosumab. 
Table II. (Contd...)

\begin{tabular}{|c|c|}
\hline Seeman et al (2010) $)^{(23)}$ & \\
\hline Study design & Results \\
\hline Jadad score 5, double-blinded double-dummy active-controlled parallel-group RCT & \multirow{3}{*}{$\begin{array}{l}\text { The } p \text {-values for percentage increase in vBMD by HR-QCT were significant when } \\
\text { denosumab was compared to alendronate. } \\
\text { Distal radius: } p=0.024 \\
\text { Distal tibia: } p=0.003\end{array}$} \\
\hline Study population & \\
\hline $\begin{array}{l}\text { Ambulatory postmenopausal women; age } 50-70 \mathrm{yr} \\
\text { BMD: lumbar spine or total hip T-score of }-2.0 \text { to }-3.0 \text { by DEXA }\end{array}$ & \\
\hline $\begin{array}{l}\text { Nine sites in Argentina, Australia, Canada, France and US; } n=247 \text {; follow-up duration: } 12 \text { mth; dropout } \\
\text { rate: } 12 \%\end{array}$ & $\begin{array}{l}\text { At the distal radius at } 12 \mathrm{mth} \text { of VBMD by HR-pQCT } \\
\text { Denosumab increased total, cortical and trabecular vBMD or cortical thickness, producing } \\
\text { changes that significantly exceeded those observed with alendronate for total and cortical } \\
\text { vBMD but not trabecular vBMD or cortical thickness. }\end{array}$ \\
\hline $\begin{array}{l}\text { Exclusion: } \\
\text { 1. Unable to perform HR-pQCT }\end{array}$ & \multirow{9}{*}{$\begin{array}{l}\text { At the distal tibia at } 12 \text { mth of vBMD by HR-pQCT } \\
\text { Denosumab increased total, cortical and trabecular vBMD and cortical thickness, and did } \\
\text { so to a significantly greater extent than alendronate for total and cortical vBMD, but not for } \\
\text { trabecular vBMD and cortical thickness. } \\
\text { At the radius at } 12 \text { mth using QCT } \\
\text { Total vBMD decreased in the placebo but increased in the alendronate and denosumab } \\
\text { groups. }\end{array}$} \\
\hline 2. Fragility fracture after age 50 & \\
\hline 3. Moderate-to-severe vertebral deformity & \\
\hline 4. $25(\mathrm{OH}) \mathrm{D}<12 \mathrm{ng} / \mathrm{mL}$ & \\
\hline 5. Conditions affecting bone metabolism & \\
\hline 6. Contraindications to alendronate & \\
\hline 7. Prior IV BP/fluoride/strontium & \\
\hline 8. Cumulative oral $\mathrm{BP}>3 \mathrm{mth}$ & \\
\hline $\begin{array}{l}\text { 9. } \mathrm{BP}>1 \mathrm{mth} \text { within the past year } \\
\text { 10. Any use of } \mathrm{BP} \text { within } 3 \mathrm{mth} \text { of randomisation }\end{array}$ & \\
\hline Intervention & \multirow{15}{*}{$\begin{array}{l}\text { Bone turnover markers } \\
\text { CTX decreased slightly in the placebo group and substantially in the alendronate and } \\
\text { denosumab groups. Reduction in CTX occurred more rapidly and was greater with } \\
\text { denosumab than with alendronate. P1NP suppression was slower than that of CTX in the } \\
\text { denosumab group; the nadir occurred by } 3 \mathrm{mth} \text {, and suppression lessened by the end of } \\
\text { the 6-mth dosing interval. }\end{array}$} \\
\hline Intervention & \\
\hline SC denosumab 60 mg 6 mthly $(n=83)$ & \\
\hline Comparator & \\
\hline Oral alendronate 70 mg weekly $(n=82)$ OR placebo $(n=82)$ & \\
\hline Outcome measure & \\
\hline Primary & \\
\hline Quantitative analysis of vBMD of the total, cortical, trabecular BMD at: & \\
\hline 1. HR-pQCT at distal radius & \\
\hline 2. HR-pQCT at distal tibia & \\
\hline 3. $\mathrm{QCT}$ at distal radius & \\
\hline Secondary & \\
\hline Bone turnover markers: & \\
\hline 1. CTX & \\
\hline 2. P1NP & \\
\hline
\end{tabular}


Table II. (Contd...)

\begin{tabular}{|c|c|c|c|c|}
\hline \multicolumn{5}{|l|}{ Recknor et al (2013) } \\
\hline Study design & \multicolumn{4}{|l|}{ Results } \\
\hline Jadad score 3, open-label parallel-group RCT & \multirow{3}{*}{ Location } & \multirow{2}{*}{\multicolumn{2}{|c|}{$\begin{array}{l}\text { Mean change in BMD at } \\
12 \mathrm{mth}(\%)\end{array}$}} & \multirow{3}{*}{$\begin{array}{l}\text { Treatment } \\
\text { difference (\%); } \\
\text { p value }\end{array}$} \\
\hline Study population & & & & \\
\hline \multirow{3}{*}{$\begin{array}{l}\text { Postmenopausal women; age } \geq 55 \mathrm{yr} \\
\text { BMD: } \leq-2 \text { and } \geq-4 \text { at total hip or lumbar spine and } \geq 1 \text { at proximal femur and } \geq 2 \text { vertebrae between } \mathrm{L} 1 \text { and } \mathrm{L} 4 \\
\text { evaluable by DEXA }\end{array}$} & & Denosumab & Ibandronate & \\
\hline & Total hip & 2.3 & 1.1 & $1.1 ; p<0.001$ \\
\hline & Femoral neck & 1.7 & 0.7 & $1.0 ; p<0.001$ \\
\hline \multirow{3}{*}{$\begin{array}{l}\text { Received first prescription of daily or weekly BP therapy } \geq 1 \text { mth before screening but had either discontinued } \\
\text { BP treatment or remained on treatment but had insufficient adherence (as assessed by a score }<6 \text { on the } \\
\text { Osteoporosis-Specific Morisky Medication Adherence Scale) previously treated with oral BP therapy. }\end{array}$} & Lumbar spine & 4.1 & 2.0 & $2.1 ; p<0.001$ \\
\hline & & & & \\
\hline & \multirow[t]{2}{*}{ CTX } & \multicolumn{2}{|c|}{$\%$} & p-value \\
\hline \multirow{3}{*}{$\begin{array}{l}\text { International multicentre trial ( } 74 \text { centres in US and Europe); } \mathrm{n}=833 \text {; follow-up duration: } 12 \mathrm{mth} \text {; dropout } \\
\text { rate: } 11 \%\end{array}$} & & Denosumab & Ibandronate & \\
\hline & $1 \mathrm{mth}$ & -81.1 & -35.0 & $<0.001$ \\
\hline & $6 \mathrm{mth}$ & -60.5 & -45.4 & $<0.001$ \\
\hline \multicolumn{5}{|l|}{ Exclusion: } \\
\hline \multicolumn{5}{|l|}{$\begin{array}{l}\text { 1. Current or prior use of osteoporosis medication, except daily or weekly oral BP therapy, raloxifene, calcitonin } \\
\text { and hormone replacement therapy }\end{array}$} \\
\hline \multicolumn{5}{|l|}{$\begin{array}{l}\text { 2. Use of medications affecting bone metabolism } \leq 3 \mathrm{mth} \text { before screening; current enrolment } \leq 1 \mathrm{mth} \text { since } \\
\text { completion of other investigational trial drugs }\end{array}$} \\
\hline \multicolumn{5}{|l|}{$\begin{array}{l}\text { 3. Malignancy within the last } 5 \mathrm{yr} \text {, except fully resected basal or squamous cell carcinoma, cervical or breast } \\
\text { carcinoma in situ }\end{array}$} \\
\hline \\
\hline \multicolumn{5}{|l|}{ Intervention } \\
\hline \multicolumn{5}{|l|}{ SC denosumab $60 \mathrm{mg}$ every $6 \mathrm{mth}(\mathrm{n}=417)$} \\
\hline \multicolumn{5}{|l|}{ Comparator } \\
\hline \multicolumn{5}{|l|}{ Oral ibandronate $150 \mathrm{mg}$ once per $\mathrm{mth}(\mathrm{n}=416)$} \\
\hline \multicolumn{5}{|l|}{ Outcome measure } \\
\hline \multicolumn{5}{|l|}{ Primary } \\
\hline \multicolumn{5}{|l|}{ Percentage change of BMD from baseline in total hip using DEXA } \\
\hline \multicolumn{5}{|l|}{ Secondary } \\
\hline 1. Percentage change from baseline in femoral neck and lumbar spine BMD at Month 12 using DEXA & & & & \\
\hline 2. Percentage change from baseline in CTX at Month 1 and 6 & & & & \\
\hline
\end{tabular}


Table II. (Contd...)

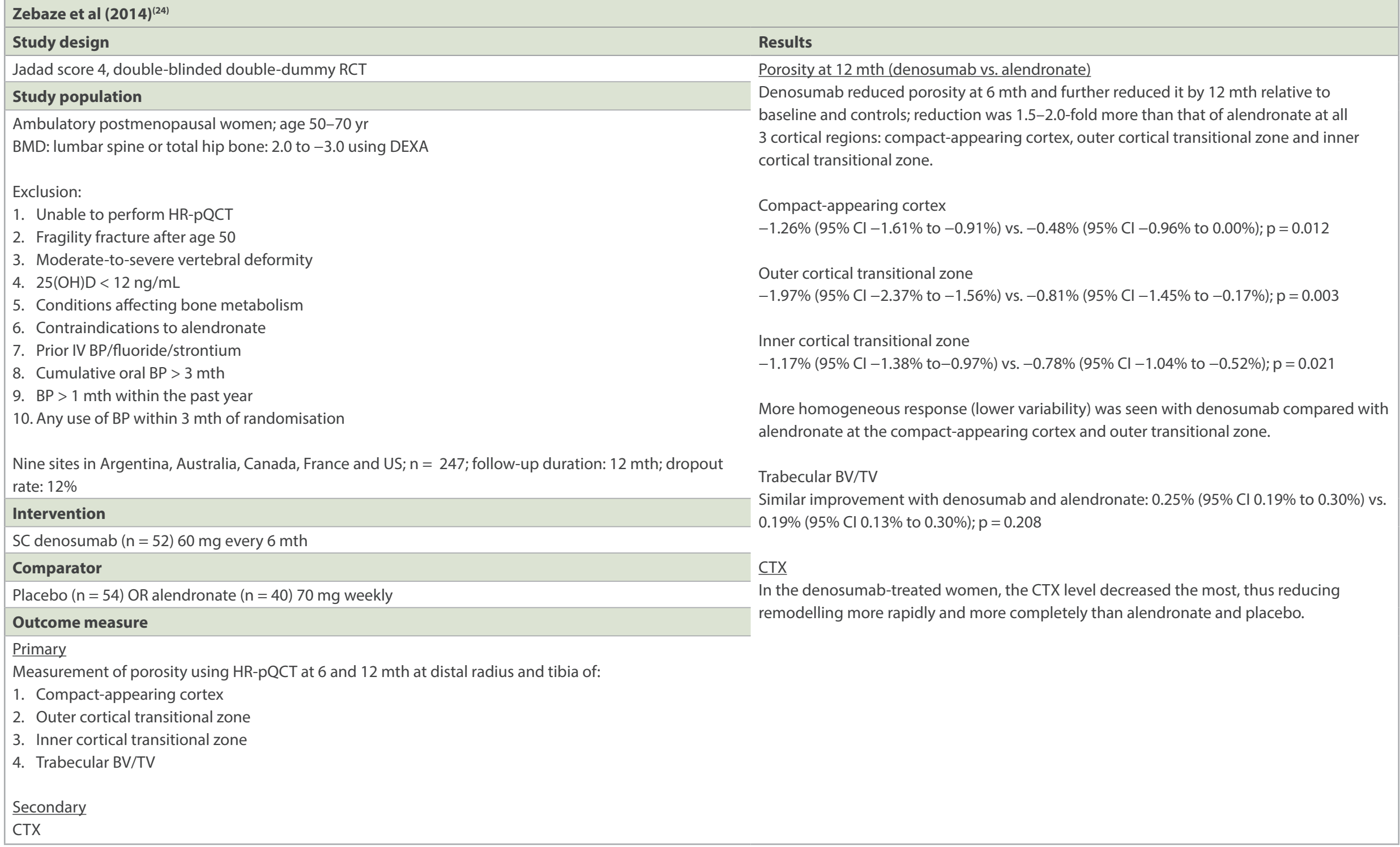


Table II. (Contd...)

\begin{tabular}{|c|c|c|c|}
\hline \multicolumn{4}{|l|}{ Anastasilakis et al (2015) $)^{(25)}$} \\
\hline Study design & \multicolumn{3}{|l|}{ Results } \\
\hline Jadad score $3, \mathrm{RCT}$ & \multicolumn{3}{|c|}{ Mean increase in BMD at lumbar spine at $12 \mathrm{mth}$} \\
\hline Study population & Denosumab (\%) & Zoledronic acid (\%) & p-value \\
\hline \multirow{2}{*}{$\begin{array}{l}\text { Ambulatory postmenopausal Caucasian women in Greece; average age } 63 \text { yr } \\
B M D \leq 2.0 \text { at lumbar spine and/or non-dominant femoral neck using DEXA }\end{array}$} & 4.5 & 4.4 & 0.560 \\
\hline & \multicolumn{3}{|c|}{ Denosumab vs. zoledronic acid } \\
\hline \multirow{2}{*}{$\begin{array}{l}\text { All patients had a single dose of zoledronic acid infusion for the first time } 1 \mathrm{yr} \text { ago. } \\
\mathrm{n}=64 \text {; follow-up duration: } 12 \mathrm{mth} \text {; dropout rate: } 9.3 \%\end{array}$} & Bone turnover marker & \multicolumn{2}{|l|}{ p-value } \\
\hline & \multicolumn{3}{|l|}{ CTX } \\
\hline \multirow{5}{*}{$\begin{array}{l}\text { Exclusion: } \\
\text { 1. Age }<40 \\
\text { 2. Any bone and mineral disorder other than osteoporosis, severe liver or kidney disease, premature } \\
\text { ovarian failure, uncontrolled thyroid disease, malignancy, or any musculoskeletal injury or surgical } \\
\text { procedure } 6 \text { mth prior to baseline or plan to undergo dental surgery } \\
\text { 3. History or concomitant medications that could affect bone metabolism }\end{array}$} & At $3 \mathrm{mth}$ & \multicolumn{2}{|c|}{ Larger decrease in denosumab $(p=0.001)$} \\
\hline & \multicolumn{3}{|l|}{ P1NP } \\
\hline & At $3 \mathrm{mth}$ & \multicolumn{2}{|c|}{ Larger decrease in denosumab $(p=0.001)$} \\
\hline & At $6 \mathrm{mth}$ & \multicolumn{2}{|c|}{ Larger decrease in denosumab $(p=0.021)$} \\
\hline & At $12 \mathrm{mth}$ & \multicolumn{2}{|c|}{ Larger decrease in denosumab $(p=0.042$} \\
\hline \multicolumn{4}{|l|}{ Intervention } \\
\hline \multicolumn{4}{|l|}{ SC denosumab $(n=34) 60 \mathrm{mg}$ every $6 \mathrm{mth}$} \\
\hline \multicolumn{4}{|l|}{ Comparator } \\
\hline \multicolumn{4}{|l|}{ A single $5 \mathrm{mg}$ dose of IV zoledronic acid infusion $(n=30)$} \\
\hline \multicolumn{4}{|l|}{ Outcome measure } \\
\hline \multicolumn{4}{|l|}{ Primary } \\
\hline \multicolumn{4}{|l|}{ Secondary } \\
\hline Bone turnover markers & & & \\
\hline
\end{tabular}

25(OH)D: 25-hydroxy vitamin D; ALP: alkaline phosphatase; BMD: bone mineral density; BP: bisphosphonate; BV: bone volume; BV/TV: bone volume density; Cl: confidence interval; CrCl: creatinine clearance; CT: computed tomography; CTX: serum C-telopeptide of cross-linked collagen; DEXA: dual-energy X-ray absorptiometry; GFR: glomerular filtration rate; HR-pQCT: high-resolution peripheral quantitative computed tomography; iPTH: intact parathyroid hormone; IV: intravenous; P1NP: procollagen type $1 \mathrm{~N}$-terminal propeptide; PTH: parathyroid hormone; Q3M: every three months; Q6M: every six months; QCT: quantitative computed tomography; RCT: randomised controlled trial; SC: subcutaneous; US: United States; VBMD: volumetric bone mineral density 


\section{DISCUSSION}

In this review, the efficacy and safety of denosumab was compared with that of other oral bisphosphonates in postmenopausal women with low bone density. In four out of six study cohorts, ${ }^{(20-25)}$ denosumab was superior to alendronate and ibandronate in terms of efficacy. They also found that having subcutaneous injections of denosumab every six months leads to good bone mineralisation.

As shown by Zebaze et al, ${ }^{(24)}$ denosumab causes less porosity than alendronate. Denosumab is more effective on cortical bone than trabecular bone. This is important as $80 \%$ of bone is cortical and $70 \%$ of all appendicular bone loss is cortical(26), occuring mainly by intracortical remodelling. In addition, $80 \%$ of fractures in women over 65 years of age are non-vertebral. Given the aforementioned factors, it stands to reason that denosumab is effective in reducing intracortical bone remodelling in women with postmenopausal osteoporosis.

Medication adherence has been shown to be better with denosumab than with bisphosphonates. A study by Kendler et $\mathrm{al}^{(27)}$ reported greater treatment satisfaction when patients transitioned to denosumab as compared to switching to a monthly oral bisphosphonate. Another study by Palacios et al ${ }^{(28)}$ showed that participants preferred denosumab to alendronate while on treatment and had more positive perceptions of it, which were also associated with better adherence. Thus, denosumab can be considered as a preferred choice for use in osteoporosis treatment among postmenopausal women.

Denosumab costs approximately SGD 800 per year for two injections, or nearly eight times more than a yearly supply of generic bisphosphonates. Besides the cost, the fear of needles may be a deterring factor as well. These are important considerations that need to be discussed with the patient to allow her to make an informed choice, and to individualise the treatment for postmenopausal osteoporosis. Nevertheless, for those with intolerance or contraindications to bisphosphonate, denosumab is an effective alternative. In terms of bone turnover markers, all studies consistently showed that serum CTX was lowered in the denosumab group. By reducing remodelling, denosumab decreases the microarchitectural deterioration and porosity that cause osteoporosis.

This study was interested in bone strength improvement as a clinical outcome, rather than the patient-centred outcome of fracture risk reduction. We did not consider fracture reduction as the primary outcome measure in patient care. Fracture reduction was compared in a study conducted by Nakamura et al in 2014 ${ }^{(29)}$ on Japanese postmenopausal women and men with osteoporosis. Two arms of the study were double-blinded to denosumab and placebo, while the third arm was an open-label alendronate group. Denosumab was shown to significantly reduce the risk of new or worsening vertebral fracture by $65.7 \%$; the incidence of new or worsening vertebral fracture was $3.6 \%$ with denosumab and $10.3 \%$ with a placebo at 24 months (hazard ratio $0.343 ; 95 \% \mathrm{CI}$ $0.194-0.606 ; p=0.0001)$. Another similar study, the FREEDOM (Fracture Reduction Evaluation of Denosumab in Osteoporosis Every 6 Months) trial, ${ }^{(30)}$ showed reduction in vertebral and non- vertebral fractures with the use of denosumab. However, these two trials did not directly compare denosumab and alendronate in fracture risk reduction. A recent review conducted by Benjamin et $\mathrm{al}^{(31)}$ compared the efficacy of denosumab with that of bisphosphonates in postmenopausal osteoporosis. However, the inclusion criteria was not robust and some potentially significant articles were excluded. In comparison, this review selected more articles based on our inclusion criteria, a Jadad score of 3 and above.

Adverse events, based on incidence rates of malignancy and infections, were not significantly different between the denosumab-treated group and the bisphosphonate-treated group in the studies. There were no reports of osteonecrosis of the jaw, atypical femur fracture or hypocalcaemia following the use of denosumab, and it was not contraindicated in patients with renal impairment.

The studies analysed in this review had some limitations. The study on bone porosity ${ }^{(24)}$ had missing data that was handled by leaving out a large number of patients, so that $41 \%$ of the participants were not analysed. However, the baseline characteristics of the three groups were similar. In addition, the follow-up rate was as low as $70 \%$ in some of the studies. ${ }^{(20)}$ Better follow-up could have contributed to a better evaluation of the outcomes. Future studies can be conducted with various bisphosphonates such as risedronate (apart from alendronate, ibandronate and zoledronic acid), to study the use of bisphosphonates or denosumab in postmenopausal women in both improving bone strength and reducing fracture. The longterm safety profile of denosumab also needs further evaluation.

In conclusion, denosumab can be used both as a first-line agent and an alternative to bisphosphonate in the treatment of postmenopausal osteoporosis. There is currently insufficient data to show that denosumab is not inferior to bisphosphonates in fracture prevention.

\section{REFERENCES}

1. Koh LK, Saw SM, Lee JJ, Leong KH, Lee J; National Working Committee on Osteoporosis. Hip fracture incidence rates in Singapore 1991-1998. Osteoporos Int 2001; 12:311-8.

2. International Osteoporosis Foundation. The Asian audit: epidemiology, costs and burden of osteoporosis in Asia 2009. Available at: https://www.iofbonehealth.org/ sites/default/files/PDFs/Audit\%20Asia/Asian_regional_audit_2009.pdf. Accessed May 3, 2016

3. Sornay-Rendu E, Boutroy S, Munoz F, Bouxsein ML. Cortical and trabecular architecture are altered in postmenopausal women with fractures. Osteoporos Int 2009; 20:1291-7.

4. Dhainaut A, Hoff M, Syversen $U$, Haugeberg G. Cortical hand bone porosity and its association with distal radius fracture in middle aged and elderly women. PLoS One 2013; 8:e68405.

5. Zebaze RM, Ghasem-Zadeh A, Bohte A, et al. Intracortical remodelling and porosity in the distal radius and post-mortem femurs of women: a cross-sectional study. Lancet 2010; 375:1729-36.

6. Boyle WJ, Simonet WS, Lacey DL. Osteoclast differentiation and activation. Nature 2003; 423:337-42.

7. Bone HG, Bolognese MA, Yuen CK, et al. Effects of denosumab on bone mineral density and bone turnover in postmenopausal women. J Clin Endocrinol Metab 2008; 93:2149-57.

8. Lacey DL, Timms E, Tan HL, et al. Osteoprotegerin ligand is a cytokine that regulates osteoclast differentiation and activation. Cell 1998; 93:165-76.

9. Messori A, Fadda V, Maratea D, Trippoli S, Marinai C. Anti-reabsorptive agents in women with osteoporosis: determining statistical equivalence according to evidence-based methods. J Endocrinol Invest 2014; 37:769-73.

10. Migliore A, Broccoli S, Massafra U, Cassol M, Frediani B. Ranking antireabsorptive 
agents to prevent vertebral fractures in postmenopausal osteoporosis by mixed treatment comparison meta-analysis. Eur Rev Med Pharmacol Sci 2013 17:658-67.

11. Mandema JW, Zheng J, Libanati C, Perez Ruixo JJ. Time course of bone mineral density changes with denosumab compared with other drugs in postmenopausal osteoporosis: a dose-response-based meta-analysis. J Clin Endocrinol Metab 2014; 99:3746-55.

12. Murad MH, Drake MT, Mullan RJ, et al. Clinical review. Comparative effectiveness of drug treatments to prevent fragility fractures: a systematic review and network meta-analysis. J Clin Endocrinol Metab 2012; 97:1871-80.

13. Brown JP, Roux C, Ho PR, et al. Denosumab significantly increases bone minera density and reduces bone turnover compared with monthly oral ibandronate and risedronate in postmenopausal women who remained at higher risk for fracture despite previous suboptimal treatment with an oral bisphosphonate. Osteoporos Int 2014; 25:1953-61.

14. Lin T, Wang C, Cai XZ, et al. Comparison of clinical efficacy and safety between denosumab and alendronate in postmenopausal women with osteoporosis: a meta-analysis. Int J Clin Pract 2012; 66:399-408.

15. Roux C, Hofbauer LC, Ho PR, et al. Denosumab compared with risedronate in postmenopausal women suboptimally adherent to alendronate therapy: efficacy and safety results from a randomized open-label study. Bone 2014; 58:48-54

16. Beck TJ, Lewiecki EM, Miller PD, et al. Effects of denosumab on the geometry of the proximal femur in postmenopausal women in comparison with alendronate. J Clin Densitom 2008; 11:351-9.

17. McClung MR, Lewiecki EM, Cohen SB, et al; AMG 162 Bone Loss Study Group. Denosumab in postmenopausal women with low bone mineral density. N Eng J Med 2006; 354:821-31.

18. Lewiecki EM, Miller PD, McClung MR, et al; AMG 162 Bone Loss Study Group. Two-year treatment with denosumab (AMG 162) in a randomized phase 2 study of postmenopausal women with low BMD. J Bone Miner Res 2007; 22:1832-41.

19. Miller PD, Bolognese MA, Lewiecki EM, et al; Amg Bone Loss Study Group. Effect of denosumab on bone density and turnover in postmenopausal women with low bone mass after long-term continued, discontinued, and restarting of therapy: a randomized blinded phase 2 clinical trial. Bone 2008; 43:222-9.

20. Brown JP, Prince RL, Deal C, et al. Comparison of the effect of denosumab and alendronate on BMD and biochemical markers of bone turnover in postmenopausal women with low bone mass: a randomized, blinded, phase 3 trial. J Bone Miner Res 2009; 24:153-61.

21. Kendler DL, Roux C, Benhamou CL, et al. Effects of denosumab on bone mineral density and bone turnover in postmenopausal women transitioning from alendronate therapy. J Bone Miner Res 2010; 25:72-81.

22. Recknor C, Czerwinski E, Bone HG, et al. Denosumab compared with ibandronate in postmenopausal women previously treated with bisphosphonate therapy: a randomized open-label trial. Obstet Gynecol 2013; 121:1291-9.

23. Seeman E, Delmas PD, Hanley DA, et al. Microarchitectural deterioration of cortical and trabecular bone: differing effects of denosumab and alendronate. J Bone Miner Res 2010; 25:1886-94.

24. Zebaze RM, Libanati C, Austin M, et al. Differing effects of denosumab and alendronate on cortical and trabecular bone. Bone 2014; 59:173-9.

25. Anastasilakis AD, Polyzos SA, Gkiomisi A, et al. Denosumab versus zoledronic acid in patients previously treated with zoledronic acid. Osteoporos Int 2015 ; 26:2521-7.

26. Kanis JA, Borgstrom F, Zethraeus N, Johnell O, Oden A, Jonsson B. Intervention thrsholds for osteoporosis in the UK. Bone 2005: 36:22-32.

27. Kendler DL, Macarios D, Lillestol MJ, et al. Influence of patient perceptions and preferences for osteoporosis medication on adherence behavior in the Denosumab Adherence Preference Satisfaction study. Menopause 2014; 21:25-32.

28. Palacios S, Agodoa I, Bonnick S, et al. Treatment satisfaction in postmenopausal women suboptimally adherent to bisphosphonates who transitioned to denosumab compared with risedronate or ibandronate. J Clin Endocrinol Metab 2015; 100:E487-92

29. Nakamura T, Matsumoto T, Sugitomo T, et al. Clinical Trials Express: fracture risk reduction with denosumab in Japanese postmenopausal women and men with osteoporosis: denosumab fracture intervention randomized placebo controlled trial (DIRECT). J Clin Endocrinol Metab 2014; 99:2599-607.

30. Papapoulos S, Chapurlat R, Libanati C, et al. Five years of denosumab exposure in women with postmenopausal osteoporosis: results from the first two years of the FREEDOM extension. J Bone Miner Res 2012; 27:694-701.

31. Benjamin B, Benjamin MA, Swe M, Sugathan S. Review on the comparison of effectiveness between denosumab and bisphosphonates in post-menopausal osteoporosis. Osteoporos Sarcopenia 2016; 2:77-81. 